\title{
IMPLEMENTATION OF NEURAL NETWORK MODELS TO PREDICT RESISTANCE FLOW THROUGH POROUS MEDIA WITH CONVERGENT BOUNDARIES
}

\author{
N. Bhanu Prakasham Reddy ${ }^{1}$, S. Krishnaiah ${ }^{2}, \quad$ M. Ramakrishna Reddy ${ }^{3}$ \\ ${ }^{1}$ Assistant Executive Engineer, Irrigation \& CAD Department, Minor Irrigation, Irrigation \\ Division, Srikalahasti - 517644, Chittoor District, Andhra Pradesh State, India, \\ ${ }^{2}$ Professor of Civil Engineering, J.N.T.U.A. College of Engineering, Anantapur - 515002, \\ Andhra Pradesh State, India \\ ${ }^{3}$ Professor of Earth Science, Yogivemana University, Kadapa - 516004, Y.S.R. District, \\ Andhra Pradesh, India
}

\begin{abstract}
Experimental and Neural network modeling investigation were completed to study the resistance to non uniform flow through porous media with convergent boundaries. The Experimental observations were made with "Convergent Flow Permeameter" using crushed rock as the media and water as fluid to anlyse the resistance of flowing fluid with different radial lines and with different ratio of radii. The present investigation aims to develop NNCB models to predict the optimal solution by its ability to capture non linear interacts among various parameters of the system. Feed Forward Back Propagation Neural Network models have been used in the present study for prediction of resistance flow at different radial lines with different ratios of radii and also to predict the relationship between friction factor $\left(f_{k}\right)$ and Reynolds number $\left(R_{k}\right)$ for flow in porous media with converging boundaries, using intrinsic permeability as the characteristic length. The results shows that the ANNs can be very efficient tools for predicting resistance flow and also it is possible to obtain good ANN model performance even with extremely simplified architectures involving a very few input variables.
\end{abstract}

Keywords: Friction Factor, Reynolds Number, Convergent Flow Permeameter, Porous Media, Neural Network 


\section{INTRODUCTION}

Study of flow through porous media has been attracting considerable attention for a long time. The resistance of non uniform flow through the tortuous passage of a porous media with convergent boundaries assumes an almost indescribable complexity. The significant contribution made by the authors to Seepage flow through porous media, any fact relating directly or indirectly to its flow and contributing to a greater understanding of the problems involved is of prime concern. Recently, artificial neural networks (ANNs) have emerged as an attractive and easy to implement alternative to solve complex problems efficiently. A look at the field situation involving non-Darcy seepage flow indicates that majority of them are of converging flow configuration. The study of the fluids through porous media is important in flow through rock fill dames and banks, flow through filters, flow in the area adjacent to a pumping well and flow through fissured rocks in Civil Engineering, geology, petroleum and other related fields.

Darcy (1856) related velocity of flow and hydraulic gradient by conducting experiments and arrived at an equation given by

$$
\mathrm{V}=\mathrm{KI}
$$

where $\mathrm{V}=$ macroscopic velocity or seepage velocity; $\mathrm{I}=$ hydraulic gradient, and $\mathrm{K}$ is the coefficient of permeability which depends upon the particle size and shape, and other factors like void ratio, structure of the soil mass, fluid properties etc.

Forchheimer (1901) proposed an equation in a quadratic form as,

$$
\mathrm{I}=\mathrm{aV}+\mathrm{b} \mathrm{V}^{2}
$$

for the non-Darcy regime of flow, in which $\mathbf{a}$ and $\mathbf{b}$ are the coefficients determined by the properties of the fluid and porous media and are known as Darcy and non-Darcy parameters.

The investigations carried out by Ward (1964) require special attention. Ward expressed dimensionally the equation for both laminar and turbulent flows in porous medium using square root of intrinsic permeability $\sqrt{\mathrm{k}}$ as the characteristic length as

$$
I=\frac{\mu V}{\rho g k}+\frac{C_{w} V^{2}}{g \sqrt{k}}
$$

in which I is hydraulic gradient, $\mathrm{k}$ is intrinsic permeability, $\rho$ is density of fluid, $\mu$ is dynamic viscosity of fluid, $\mathrm{C}_{\mathrm{W}}$ is media constant and $\mathbf{g}$ is acceleration due to gravity. Comparing Forchheimer Eq. (2) with Eq. (3), Ward obtained expressions for $\mathbf{a}$ and $\mathbf{b}$ as 


$$
\begin{gathered}
a=\frac{\mu}{\rho g k} \\
b=\frac{C_{W}}{g \sqrt{k}}
\end{gathered}
$$

Defining frictioin factor $f_{K}$ as $\frac{\operatorname{Ig} \sqrt{\mathrm{k}}}{\mathrm{V}^{2}}$ and Reynolds number $\mathrm{R}_{\mathrm{k}}$ as $\frac{\mathrm{V} \sqrt{\mathrm{k}}}{\mathrm{v}}$, Ward obtained the relationship between friction factor and Reynolds number as

$$
\mathrm{F}_{\mathrm{k}}=\frac{1}{\mathrm{R}_{\mathrm{k}}}+\mathrm{C}_{\mathrm{w}}
$$

Mc Corquodale (1970) and Nasser (1970) conducted experiments on converging permeameter and assumed that convergence of streamlines mainly affects only non-Darcy component of Forchheimer equation and assumes that Darcy parameter is same for both parallel and converging flow. Venkataraman and Rao (1998) developed theoretical curves for flow through porous media with parallel boundaries and related friction factor $\left(\mathrm{F}_{\mathrm{K}}\right)$ and Reynolds number $\left(\mathrm{R}_{\mathrm{K}}\right)$ and the media constant $\mathrm{C}_{\mathrm{w}}$ to obtain a set of curves, similar to Moody diagram used for pipe flow. Reddy and Rao (2003) developed theoretical curves for flow through porous media with converging boundaries and related predicted friction factor $\left(\mathrm{F}_{\mathrm{K}}\right)$ and Reynolds number $\left(\mathrm{R}_{\mathrm{K}}\right)$ by using neural network models to obtain a set of curves, similar to Moody diagram used for pipe flow. Reddy and Rao (2006) studied the effect of convergence on linear and non-linear parameter for different radial flow lines with different ratios of radii and showed that both $\mathbf{a}$ and $\mathbf{b}$ are varied along the radial direction of flow with different ratio of radii. Reddy (2006) studied the effect of convergence factors $C_{A}$ and $C_{B}$ on linear parameter, $\mathbf{a}$ and non-linear parameter, $\mathbf{b}$ for central radial flow line in a convergent flow permeameter and also investigated the relationship between friction factor $\left(\mathrm{F}_{\mathrm{k}}\right)$ and Reynolds number $\left(\mathrm{R}_{\mathrm{k}}\right)$ with $\mathrm{C}_{\mathrm{A}}$ and $\mathrm{C}_{\mathrm{B}}$ for different rate of flows (Q). Reddy (2006) studied the variation of the friction factor and Reynolds number with different ratios of the radii (R1/R2) and for different convergent angles $(\theta)$ of a permeameter. Reddy and Reddy (2007) developed curves relating friction factor $\left(F_{k}\right)$ and Reynolds number $\left(R_{k}\right)$ with efficiency $(\eta)$ for different rate of flows of the test section of permeameter. Reddy and Reddy (2010) developed curves relating friction factor $\left(F_{k}\right)$ and Reynolds number $\left(R_{k}\right)$ with Power $(P)$ for different rate of flows of the test section of permeameter and also studied the variation of Darcy Parameter, a and Non-darcy Parameter, b with Power (P).

The aim of the present paper is to

1. Implement NNCB models on Convergent Flow through Porous Media to predict the relation between friction factor and Reynolds Number and compare with the experimental results. 
2. Obtain the variation of intrinsic permeability, friction factor and Reynolds number with different ratio of radii.

3. Obtain the curves relating friction factor and Reynolds number for different $\mathrm{C}_{\mathrm{w}}$ values taken as third parameter using experimental data and implement the NNCB models to predict the variation between $F_{k}$ and $R_{k}$ and compare with experimental results.

\section{NEURAL NETWORKS}

As per Garrett (1994), an artificial neural network is a computational mechanism able to acquire, represent and compute a mapping from one multivariate spacing of information to another given set of data representing the data. Haykin (1994) refers that a neural network is massively parallel distributed process that has a natural propensity of storing experimental knowledge and making it available for use. It resembles the brain in two respects:

1) The knowledge is acquired by the network through a learning process.

2) Interconnection strengths known as synaptic weights are used to store the Knowledge.

As per Goh (1995), the neural networks are computer models that mimic the knowledge acquisition and organizational skills of the human brain. An artificial neural network is usually defined as a network composed of large number of neurons that are interconnected, operate in parallel and learn from experience. The theory of Neural Networks was developed and based on the fact that human brain has the advantage of handling disperse and parallel distribution data efficiently. It is used for a variety of purposes like function approximation, pattern recognition, association, classification and optimization. Mathematically the working of a single neuron or node (Fig.1.) is given by

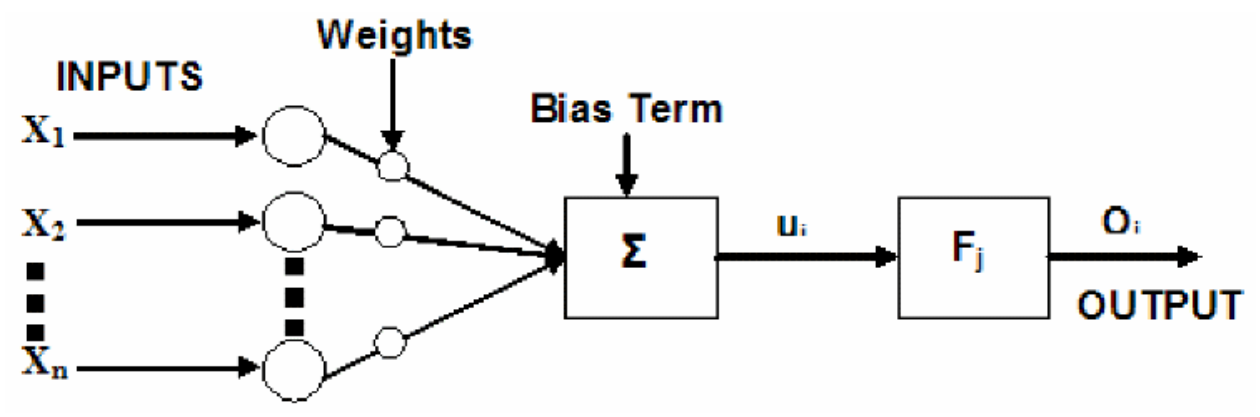

Fig.1. Model of a Single Neuron

$$
\begin{gathered}
Q_{i}=f\left\lfloor u_{i}\right\rfloor \\
\text { Where } \quad u_{i}=\sum_{i=1}^{n} W_{i j} X_{i j}-b_{i}
\end{gathered}
$$


where $\mathrm{Q}_{\mathrm{i}}=$ output from $\mathrm{i}^{\text {th }}$ Neuron, $\mathrm{W}_{\mathrm{ij}}=$ connection weight between $\mathrm{i}^{\text {th }}$ Neuron and $\mathrm{j}^{\text {th }}$ input, $\mathrm{X}_{\mathrm{ij}}=\mathrm{j}^{\text {th }}$ input value, $\mathrm{bi}=$ bias value for the $\mathrm{i}^{\text {th }}$ Neuron and summation $\Sigma$ is carried out over all input values, f[ui] $=$ transfer function, which could be a sigmoid function given by

$$
\mathrm{f}\left[\mathrm{u}_{\mathrm{i}}\right]=1 /\left(1+\exp \left(-\mathrm{u}_{\mathrm{i}}\right)\right)
$$

Applications of neural networks in Hydro informatics (1992) generally involve a Feed Forward Back propagation type network as shown in Fig.2. Such a network is found to be sufficient to approximate any continuous function. In this network input variable values are fed through the input layer of neurons. As indicated in Eq. (7) and Eq. (9) a hidden layer neuron collects each input value, multiplies it by a connection weight, adds such weighted inputs together, attaches a bias value and passes on the result through a non-linear function like that of a sigmoid one. The resulting value is fired to the output neuron, which replicate the same process and produce in the end the values of the output variables.

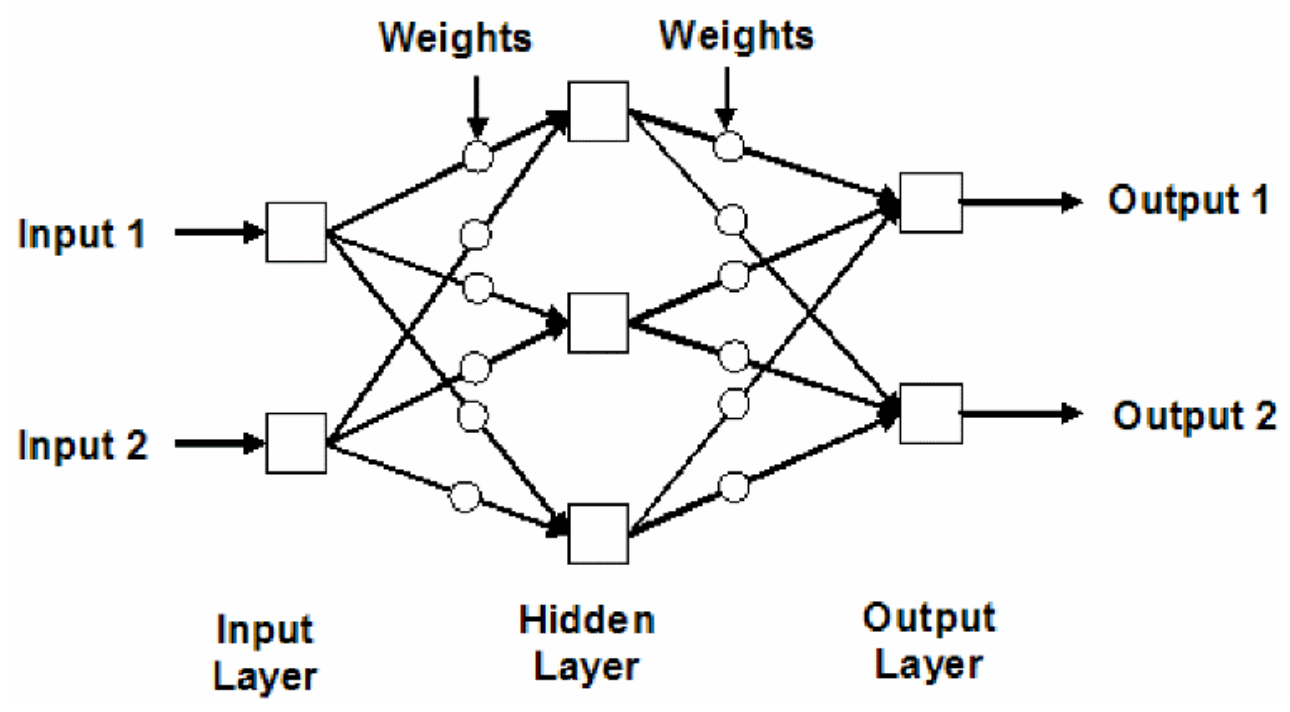

Fig.2. General Feed Forward Neural Network

\section{BACK-PROPAGATION}

Back-propagation is perhaps the most popular algorithm for training Artificial neural networks. It is essentially a gradient descent technique that minimizes the network error for function. Each input pattern of the training data set is passed through the target output and an error is computed based on equation. This error is propagated backward through the network to each node and correspondingly the connection weights are adjusted on equation: 


$$
\Delta \mathrm{W}_{\mathrm{ij}}(\mathrm{n})=-\sum * \partial \mathrm{E} / \partial \mathrm{W}_{\mathrm{ij}}+\alpha * \Delta \mathrm{W}_{\mathrm{ij}}(\mathrm{n}-1)
$$

Where $\Delta \mathrm{W}_{\mathrm{ij}}(\mathrm{n})$ and $\Delta \mathrm{W}_{\mathrm{ij}}(\mathrm{n}-1)$ are weight increments between node $\mathrm{i}$ and $\mathrm{j}$ during the $\mathrm{n}^{\text {th }}$ and $(\mathrm{n}-1)^{\text {th }}$ pass or epoch. A similar equation is written for correction of bias values. In Eq.(10), $\mathbf{E}$ and $\boldsymbol{\alpha}$ are called learning rate and momentum respectively. The momentum factor can speed up training in very flat regions of the error surface and help prevent oscillations in the weights. A learning rate is used to increase the chance of avoiding the training process being trapped in a local minimum instead of global minima. The back propagation algorithm involves two steps. The first step is a forward pass, in which the effect of the input is passed forward through the network to reach the out put layer. After the error is computed, a second step starts backward through the network. The error at the output layer is propagated back to the input layer with the weights being modified according to equation. Back propagation is a first order method based on steepest gradient descent, with the direction vector being set equal to the negative of the gradient vector. Consequently, the solution often follows a zigzag path while trying to reach a minimum error position, which may slow down the training process. It is also possible for the training process to be trapped in the local minimum despite the use of a learning rate.

\section{EXPERIMENTAL PROCEDURE:}

Experiments were conducted by the authors on a convergent permeameter of 1000 $\mathrm{mm}$ high, $150 \mathrm{~mm}$ thick and of width varying from $750 \mathrm{~mm}$ at top and $150 \mathrm{~mm}$ at bottom, using water as fluid and the angle of convergence is 0.76 radians. Piezometric tapping points are provided at $50 \mathrm{~mm}$ spacing along three Radial Lines of the permeameter and connected to a manometer board facilitated measurement of piezometric heads along the permeameter. A schematic diagram of the experimental arrangement is shown in Fig3. . A fixed flow was allowed in the system to maintain a constant head in the header tank. Head loss between any two points for each radial line located at radii $\mathrm{R}_{1}$ and $\mathrm{R}_{2}$ and the hydraulic gradient $\mathrm{I}$ between them were evaluated. The flow rate $(\mathrm{Q})$ through the media was measured by the volumetric method and the velocity of flow $\mathrm{V}$ at any radius $\mathrm{R}$ from the centre of convergence is given by

$$
\mathrm{V}=\frac{\mathrm{Q}}{\mathrm{R} \theta \mathrm{W}}
$$

Where $\mathrm{Q}$ is flow rate in $\mathrm{cm}^{3} / \mathrm{sec}, \theta$ is angle of convergence in radians and $\mathrm{W}$ is width of flow between two parallel confining surfaces of the converging permeameter. Experiments were conducted at different heads and the rate of flow through the media and the head loss in the permeameter were measured. 


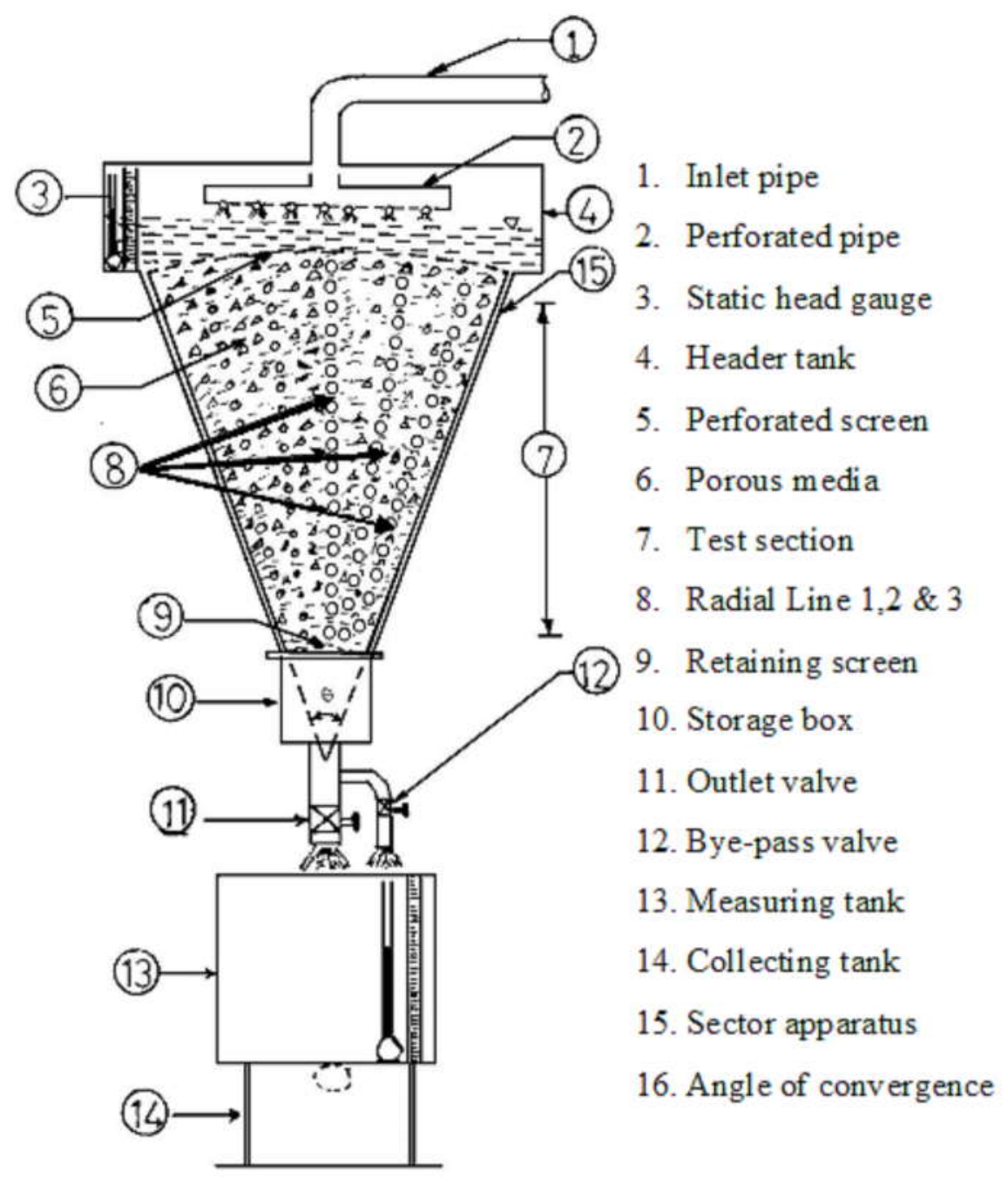

Fig.3.Details of Converging Permeameter

\section{NEURAL NETWORK MODELS FOR CONVERGENT FLOW THROUGH POROUS MEDIA}

The methodology of Neural Network was utilised for convergent flow through porous media, to predict the resistance flow at different radial lines with different ratios of radii and also to predict the relationship between friction factor $\left(F_{k}\right)$ and Reynolds number $\left(\mathrm{R}_{\mathrm{K}}\right)$ for flow in porous media with converging boundaries, using intrinsic permeability as the characteristic length. In the present study Feed Forward Back propagation algorithm was used and two different Neural Network models namely NNCB1 and NNCB2 were developed.

The first NNCB1 Model was developed for prediction of Reynolds number $\left(\mathrm{R}_{\mathrm{k}}\right)$ and the 11 input parameters are those given in Table-1 excepting Reynolds number $\left(\mathrm{R}_{\mathrm{k}}\right)$ and 
second model NNCB2 was for prediction of friction factor $\left(F_{k}\right)$ whose 11 input parameters are those in Table-1 excepting friction factor for flow through the porous media.

Table 1. Range of values of various parameters

\begin{tabular}{|c|l|c|c|c|}
\hline \multirow{2}{*}{ S.No } & \multicolumn{1}{|c|}{ Input parameters } & \multicolumn{3}{|c|}{ Range of parameters } \\
\cline { 3 - 5 } & & Radial line - 1 & Radial line - 2 & Radial line - 3 \\
\hline 1 & Velocity of Flow ( V $), \mathrm{cm} / \mathrm{sec}$ & $1.3421-2.268$ & $0.6168-2.268$ & $1.5513-2.268$ \\
\hline 2 & $\begin{array}{l}\text { Hydraulic Gradient/Velocity } \\
(\mathrm{I} / \mathrm{V}), \mathrm{sec} / \mathrm{cm}\end{array}$ & $0.0132-0.0653$ & $0.0162-0.0649$ & $0.0193-0.0637$ \\
\hline 3 & Length of reach $(\mathrm{L}), \mathrm{cm}$ & $5.0-55.0$ & $5.0-55.0$ & $5.0-55.0$ \\
\hline 4 & Head Loss $\left(\mathrm{H}_{\mathrm{L}}\right), \mathrm{cm}$ & $0.1-8.15$ & $0.05-8.10$ & $0.15-7.95$ \\
\hline 5 & Hydraulic Gradient $(\mathrm{I})$ & $0.02-0.1482$ & $0.01-0.1473$ & $0.03-0.1445$ \\
\hline 6 & Friction Factor $\left(\mathrm{F}_{\mathrm{k}}\right)$ & $0.1346-0.6317$ & $0.2746-1.021$ & $0.2889-0.5827$ \\
\hline 7 & Reynolds Number $\left(\mathrm{R}_{\mathrm{k}}\right)$ & $2.88-6.4673$ & $1.3428-6.4673$ & $3.4292-6.5989$ \\
\hline 8 & Ratios of the Radii $\left(\mathrm{R}_{1} / \mathrm{R}_{2}\right)$ & $1.05-2.25$ & $1.05-2.25$ & $1.05-2.25$ \\
\hline 9 & Rate of Flow $(\mathrm{Q}), \mathrm{cm}^{3} / \mathrm{sec}$ & $\begin{array}{c}758.43- \\
1281.65\end{array}$ & $348.54-1281.65$ & $876.6-1281.65$ \\
\hline 10 & Darcy parameter $(\mathrm{a}), \mathrm{sec} / \mathrm{cm}$ & $0.0152-0.0274$ & $0.0152-0.0258$ & $0.0146-0.0261$ \\
\hline 11 & $\begin{array}{l}\text { Non-Darcy parameter }(\mathrm{b}), \\
\text { sec }^{2} / \mathrm{cm}^{2}\end{array}$ & $0.0016-0.0168$ & $0.0048-0.0175$ & $0.005-0.0168$ \\
\hline
\end{tabular}

\section{RESULTS AND DISCUSSIONS}

\section{Prediction of Reynolds number: NN model NNCB1}

The NN model NNCB1 was developed for the prediction of Reynolds number for radial flow through homogeneous porous media. The actual range of max-min values was considered during normalization. The comparison between predicted and actual Reynolds numbers is depicted in Fig. 5 for different radial lines with different ratios of radii. In this model NNCB1, 11-5-1 is the successful network. That means the network with 11 input nodes, 5 hidden nodes in the hidden layer, 1 output node in the output layer. The NNCB1 model has 55 neurons in the first layer and 5 neurons in the second layer. The overall result is obtained with correlation coefficient of 0.994 for Radial Line - 1, correlation coefficient of 0.998 for Radial Line -2 and correlation coefficient of 0.928 for Radial Line -3 and the sum-squared error is 0.0993 achieved after 8000 cycles. 


\section{Prediction of Friction factor: NN model NNCB2}

The NN model NNCB2 was developed for prediction of friction factor. The network was trained with normalization values within actual range of max-min values. The comparison between predicted and actual friction factor is depicted in Fig. 6 for training and testing data for different radial lines with different ratios of radii. In this model NNCB2, 115-1 is the successful network. The NNCB2 model has 55 neurons in the first layer and 5 neurons in the second layer. The overall result is obtained with correlation coefficient of 0.938 for Radial Line - 1, correlation coefficient of 0.953 for Radial Line -2 and correlation coefficient of 0.928 for Radial Line -3 and the sum-squared error is 0.10 achieved after 10000 cycles.

\section{Variation of $F_{k}$ and $R_{k}$ for Different Radial Lines with Different $R_{1} / R_{2}$ ratio}

For media of certain size, the approach section a radius $\mathbf{R}_{\mathbf{1}}$ and an exit sectioin at a radius $\mathbf{R}_{\mathbf{2}}$ were arbitrarily selected. Based on the flow rates and the piezometric heads at these two points, the seepage velocity (V) and the hydraulic gradient (I) were computed. The values of the coefficients $\mathbf{a}$ and $\mathbf{b}$ for this $\mathbf{R}_{\mathbf{1}} / \mathbf{R}_{\mathbf{2}}$ ratio were then obtained from a plot of $\mathrm{I} / \mathrm{V}$ versus $\mathrm{V}$ and the values of $\mathrm{C}_{\mathrm{w}}, \mathrm{F}_{\mathrm{k}}$ and $\mathrm{R}_{\mathrm{k}}$ were computed for a given velocity (V) using the values of $\mathbf{a}$ and $\mathbf{b}$ obtained from the Eq.4 and Eq.5. Figs. 2(a-d) shows the contours of pressure head distribution for different rate of flows for crushed rock. Fig.5 and Fig.6. shows the comparison between predicted and actual Friction Factor, $F_{k}$ and Reynolds Number, $R_{k}$ for different Radial Lines with different $R_{1} / R_{2}$ ratios and observed that the predicted data with actual data is within permissible limit. Fig.7. depicts the variation of Friction Factor $\left(F_{k}\right)$ with Reynolds Number $\left(R_{k}\right)$ for Predicted and Actual Data for Different Radial Lines and Ratio of radii (R1/R2). Fig.8. shows the variation of Predicted Friction Factor $\left(\mathrm{F}_{\mathrm{k}}\right)$ and Reynolds Number $\left(\mathrm{R}_{\mathrm{k}}\right)$ for Different Radial Lines and for different Ratio of radii (R1/R2). In Fig.8, It is observed that the Friction Factor $\left(F_{k}\right)$ decreases with increase of Reynolds Number $\left(\mathrm{R}_{\mathrm{k}}\right)$ and also observed that the Friction Factor decreases with decrease of Ratio of radii (R1/R2). The same trends are also observed for other two radial lines.

\section{Variation of $\mathbf{f}_{\mathbf{k}}$ with $\mathbf{R}_{\mathbf{k}}$}

Assigning different values for $\mathrm{C}_{\mathrm{w}}, \mathrm{F}_{\mathrm{k}}$ values for different $\mathrm{R}_{\mathrm{k}}$ have been computed using Eq.(6). Figs. 9(a-c) shows the theoretical plot of Eq.(6) with $\mathrm{C}_{\mathrm{w}}$ as third parameter. When

$\mathrm{C}_{\mathrm{w}}$ is equal to zero, Eq.(6) yields Darcy's law with relation between $F_{k}$ and $R_{k}$ being inversely proportional. The inclined dashed line in Figs. 9(a-c) demarcates, approximately, the $R_{k}$ at which the flow changes from non linear transition to wholly turbulent flow. The predicted data values of $F_{k}$ and $R_{k}$ are sorted based on the values of $C_{w}$ and are plotted in Figs. 9(a-c) against the theroretical $F_{k}-R_{k}$ curve. In Figs. 9(a-c), the range of $C_{w}$ values is shown on the theoretical curve against which the predicted points of $F_{k}-R_{k}$ were plotted. The correlation is very good with all predicted points falling on the $F_{k}-R_{k}$ curve for the corresponding values of $C_{w}$. Variation of $F_{k}$ with $R_{k}$ for each $C_{w}$ value and $R_{1} / R_{2}$ ratio is 
also shown in Figs. 9(a-c) for different radial lines for experimental and predicted data from NNCB models.

\section{CONCLUSION}

Flow through porous media with converging boundaries has been analyzed and it is shown that there is a good agreement between the theoretical curve, experimental data and predicted data using NNCB models. In the present study, two Feed Forward Back Propagation Neural Network models were developed and successfully implemented and conclusions drawn are

1. The variation of $F_{k}$ and $R_{k}$ for different $C_{w}$ values and for different Radial Lines are compared with the experimental data and predicted data and observed lie on the theoretical curve.

2. The relation between $\mathrm{F}_{\mathrm{K}}$ and $\mathrm{R}_{\mathrm{K}}$ for predicted data, using the square root of intrinsic permeability as the characteristic length and $\mathrm{C}_{\mathrm{w}}$ as a parameter is shown to be similar to the Moody diagram for pipe flow. There is a good agreement between the theoretical curves and predicted data obtained from the NNCB modal.

3. The obtained results suggest that NNCB models can be effectively trained in a neural system inspite of data complexity, incompleteness and incoherence and these models are useful to predict the resistance flow for any Radial Line even with extremely simplified architectures involving a very few input variables.

\section{Acknowledgements}

The authors wish to thank the Ministry of Science \& Technology, Department of Science and Technology, New Delhi, authorities for the financial support (Grant No: SR/FTP/ETA-22/2005) rendered by them for carrying out the study and also the authors are grateful to the Management of N.B.K.R. Institute of Science \& Technology, Vidyanagar,

Nellore District for providing facilities and encouragement during the course of study.

\section{REFERENCES}

[1] Bhanu Prakasham Reddy, N., and Rama Krishna Reddy, M., " Energy loss in the flowing fluid through porous media with convergent boundaries". Journal of Indian Water Resources Society. 30(3), 30-36, 2010.

[2] Bhanu Prakasham Reddy, N., and Rama Krishna Reddy, M., " Efficiency of steady nonuniform flow through homogeneous porous media". Journal of Hydraulic Engineering. 13(2), 53-65, 2007.

[3] Bhanu Prakasham Reddy, N., "Effect of Convergent Angle on Nonlinear Flow through Porous Media”. Journal of Porous Media. 9(5), 415 - 428, 2006.

[4] Bhanu Prakasham Reddy, N., "Effect of Convergence Factors on Flow through Porous Media In Converging Boundaries”. Journal of Porous Media. 9(2), 109-126, 2006. 
[5] Bhanu Prakasham Reddy, N., and Rao., "Effect of convergence on non-linear flow in porous media," J.Hydraul. Division. 132(4), 420-427, 2006.

[6] Bhanu Prakasham Reddy, N., and Rao. (2003). " Behavior of non-linear flow and application of neural network in converging boundaries." Journal of Hydraulic Engineering 9(2)., 36-54, 2003.

[7] Darcy, H., "Les Fontaines Publiques de la ville de Dijon." Dalmont, Paris, 1856

[8] Forchheimer., “Wasserbewegung durch Boden.” Z. Ver.Deutsch. Ing., 45, 1782-1788.

[9] Garrett, J . H . Jr., "Where and why artificial neural networks are applicable in Civil Engineering”, Editorial, Jl. Computing in Civil Engineering. 8(2), 129-130, 1994.

[10] Goh, A . T . C., "Modeling soil correlations using neural networks", Jl. Computing in Civil Engineering, ASCE, New York, 9(4), 1995.

[11] Haykin, S., "Neural networks: A comprehensive foundation" . Mac-millan college Publishing Co., New York, 1994.

[12] McCorquodale, J . A., " Finite element analysis of non-Linear flow." Ph.D thesis, University of Windsor, Windsor, Canada, 1970.

[13] Nasser, M . S . S., “ Radial non-Linear flow through porous media." Master of Applied Science thesis, University of Windsor, Windsor, Canada, 1970.

[14] Rashid. ABD, AZZ. ABD and Kau-Fui Vincent Wong., "A Neural Network Approach for the determination of Aquifer parameters"., Ground water Jl., Mar-April 1992.

[15] Venkataraman, P., and Rama Mohan Rao. P., " Darcian, transitional, and turbulent flow through porous media.” J. Hydr.Engrg.124(8), 840-846, 1998.

[16] Venkataraman, P., and Rama Mohan Rao. P., "Validation of Forchheimer's law for flow through porous media with converging boundaries." J. Hydr.Engrg. 126(1), 63-71,2000.

[17] Ward, J.C., “Turbulent flow in porous media.” J. Hydr. Div. 92(5),1964.

\section{NOTATIONS}

$\mathrm{a}=$ Darcy parameter or linear parameter

$\mathrm{b}=$ Non- Darcy parameter or non linear parameter

$b_{i}=$ Bias value for the $i^{\text {th }}$ Neuron

$\mathrm{C}_{\mathrm{W}}=$ Media constants

$\mathrm{E}=$ Learning rate

$\mathrm{F}_{\mathrm{k}}=$ Friction Factor

$\mathrm{f}\left[\mathrm{u}_{\mathrm{i}}\right]=$ Transfer function

$\mathrm{g}=$ Acceleration due to gravity

$\mathrm{H}_{\mathrm{L}}=$ Head loss

$\mathrm{I}=$ Hydraulic gradient

$\mathrm{K}=$ Coefficient of permeability

$\mathrm{k}=$ Intrinsic permeability

$\mathrm{Q}=$ Rate of flow

$\mathrm{Q}_{\mathrm{i}}=$ output from $\mathrm{i}^{\text {th }}$ Neuron

$\mathrm{R}=$ Radius of the permeameter

$\mathrm{R}_{\mathrm{k}}=$ Reynolds number 
$\mathrm{S}_{\mathrm{MAX}}=$ Maximum value of parameter

$\mathrm{S}_{\text {MIN }}=$ Minimum value of parameter

$\mathrm{W}=$ Width of flow between two parallel confining surfaces of the Converging Permeameter

$\mathrm{W}_{\mathrm{ij}}=$ Connection weight between $\mathrm{i}^{\text {th }}$ Neuron and $\mathrm{j}^{\text {th }}$ input

$\Delta \mathrm{W}_{\mathrm{ij}}(\mathrm{n})=$ Weight increments between node $\mathrm{I}$ and $\mathrm{j}$ during the $\mathrm{n}^{\text {th }}$ pass

$\mathrm{V}=$ Velocity of flow

$\mathrm{X}=$ Normalised value of parameter

$X_{i j}=j^{\text {th }}$ input value

$\alpha=$ Momentum

$\mu=$ Dynamic viscosity

$v=$ Kinematic viscosity

$\rho=$ Density of the fluid

$\Sigma=$ Summation

$\theta=$ Angle of convergence in radians 


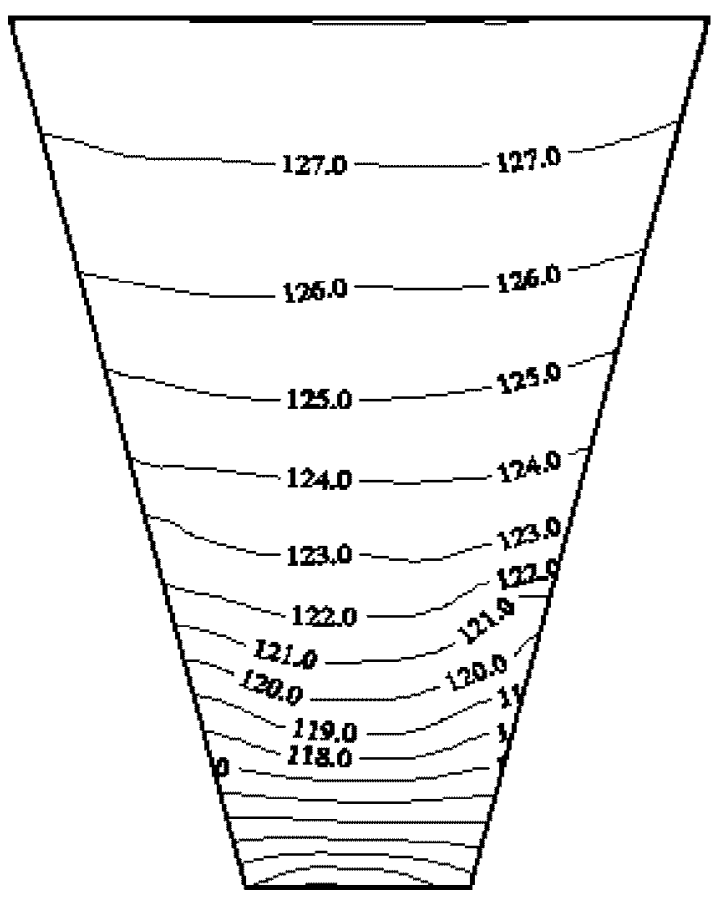

Fig.4. a. For $\mathrm{Q}=1281.64 \mathrm{cc} / \mathrm{sec}$

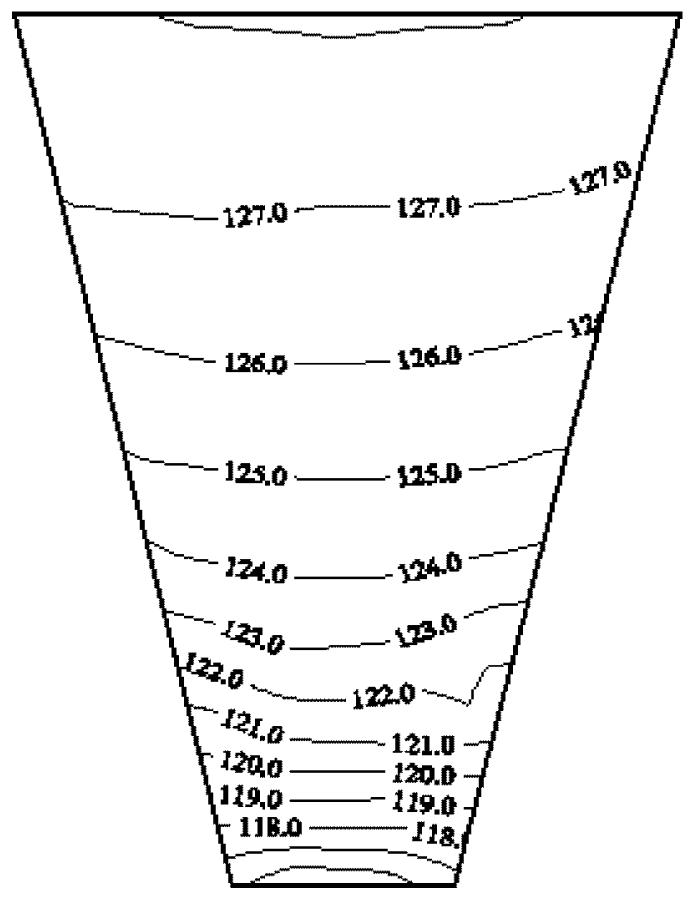

Fig.4. c. For $\mathrm{Q}=1065.79 \mathrm{cc} / \mathrm{sec}$

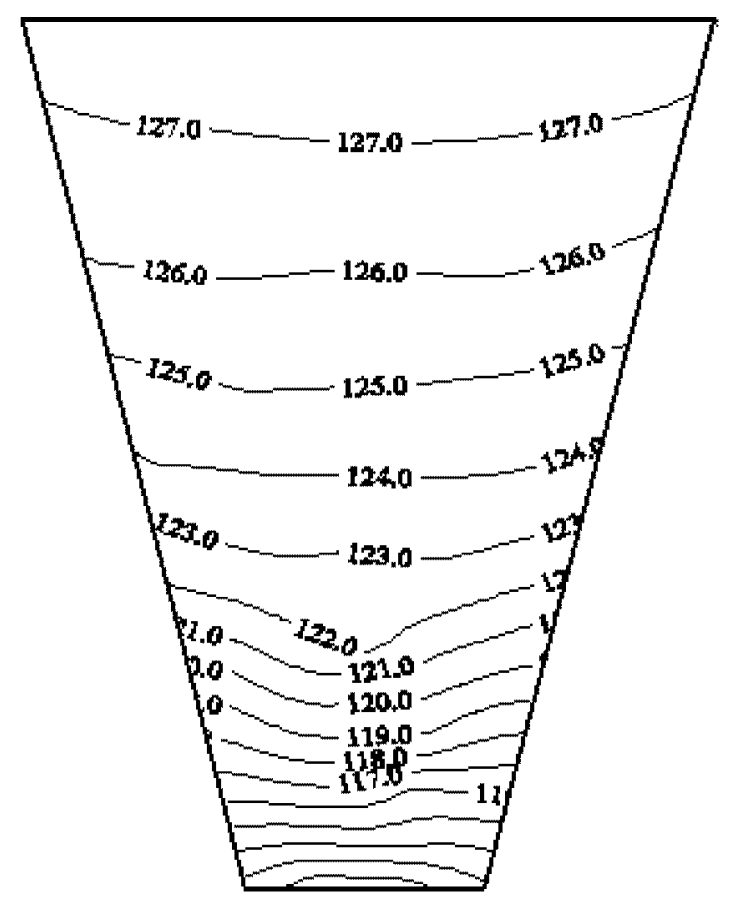

Fig.4. b. For $\mathrm{Q}=1242.33 \mathrm{cc} / \mathrm{sec}$

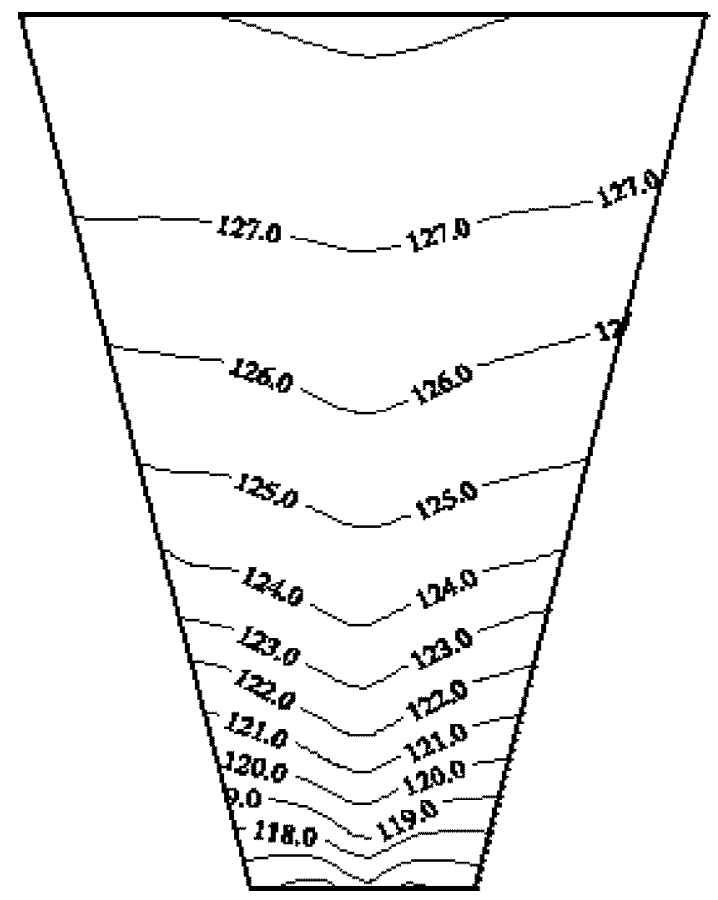

Fig.4. d. For $\mathrm{Q}=978.26 \mathrm{cc} / \mathrm{sec}$

Fig.4. Pressure Distribution for Different Rate of Flows 

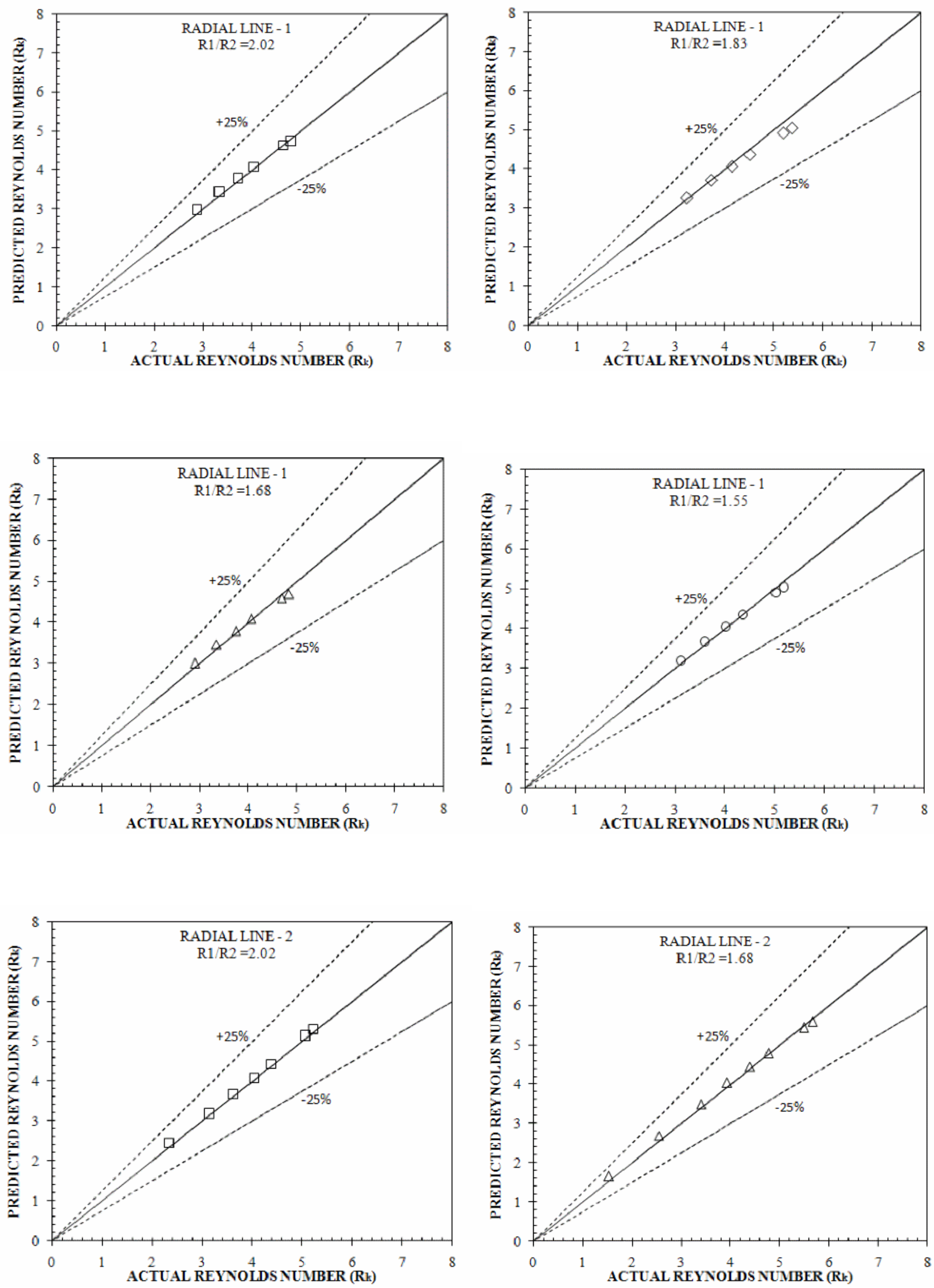

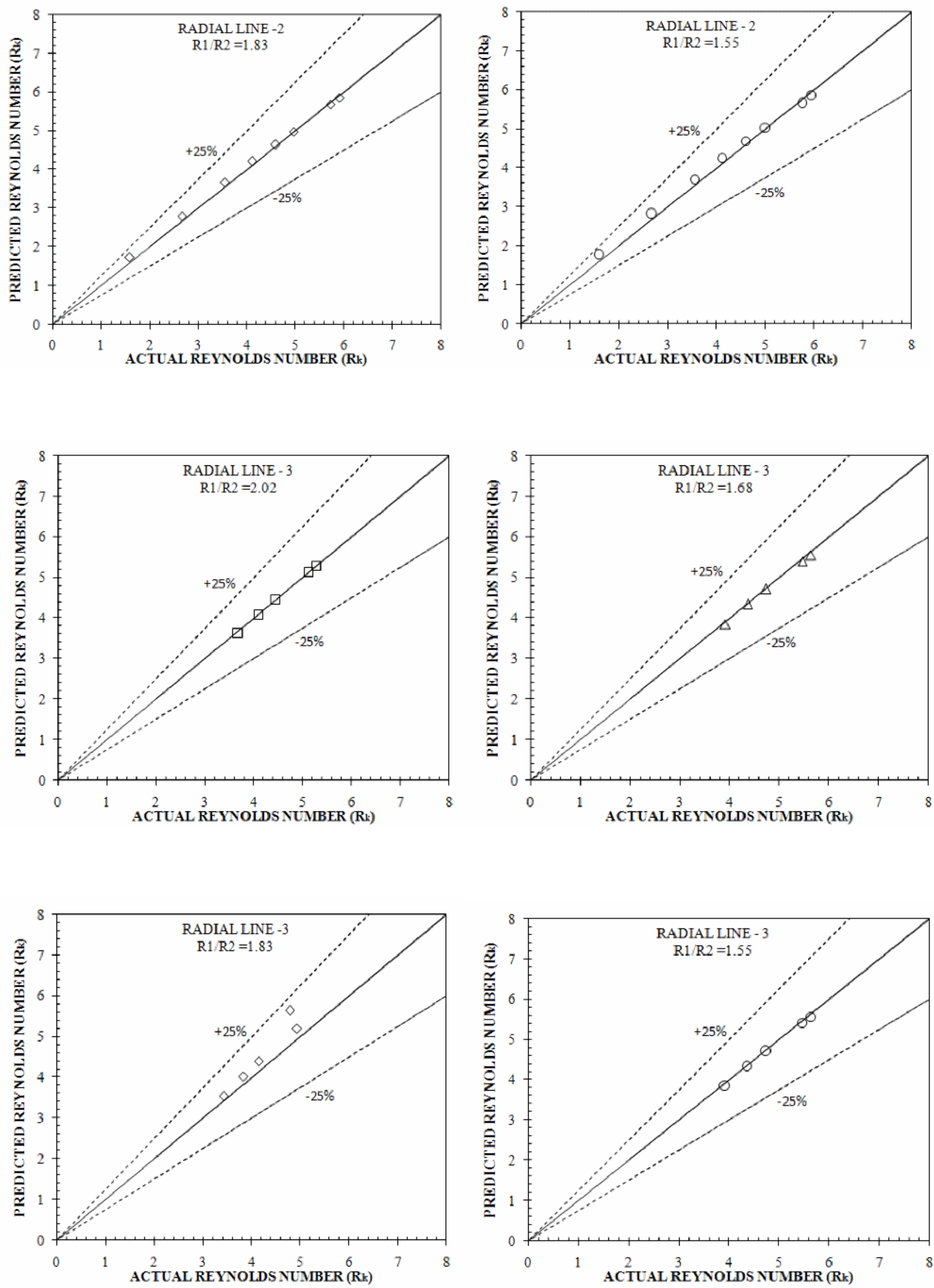

Fig.5. Actual and Predicted Reynolds Number $\left(\mathrm{R}_{\mathrm{k}}\right)$ for Different Radial Lines and Ratio of radii (R1/R2) 

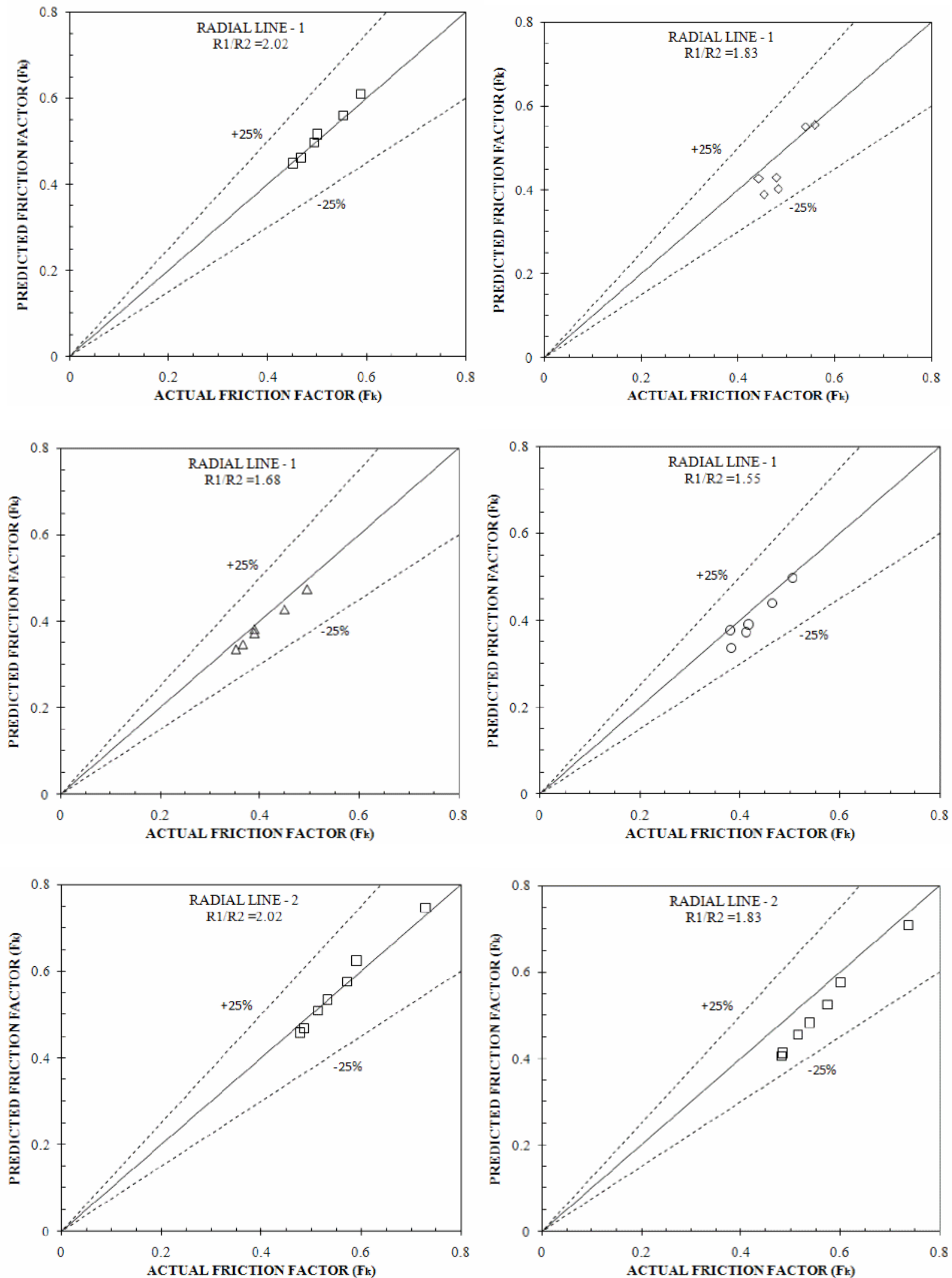

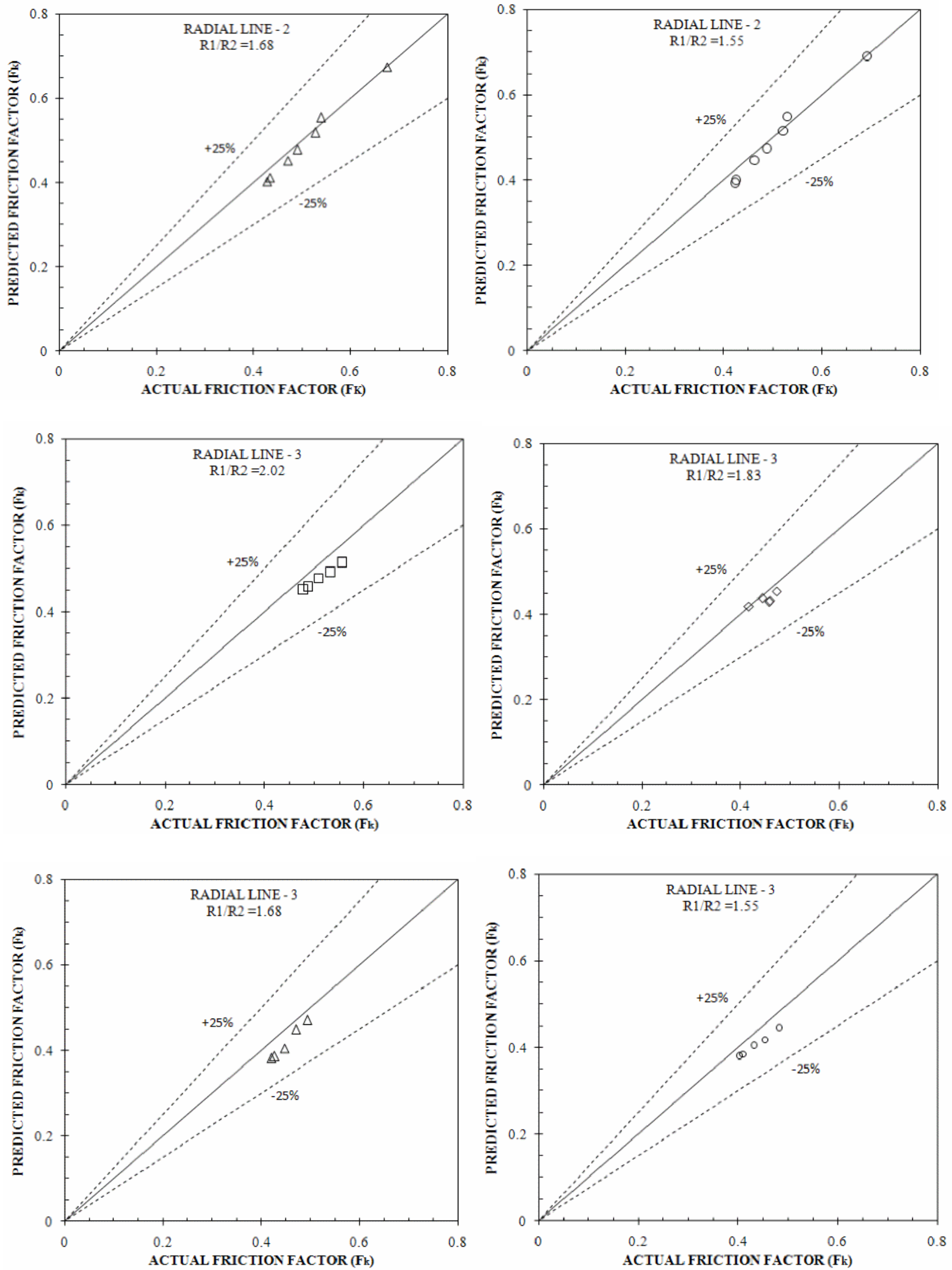

Fig.6. Actual and Predicted Friction Factor $\left(F_{k}\right)$ for Different Radial Lines and Ratio of radii (R1/R2) 

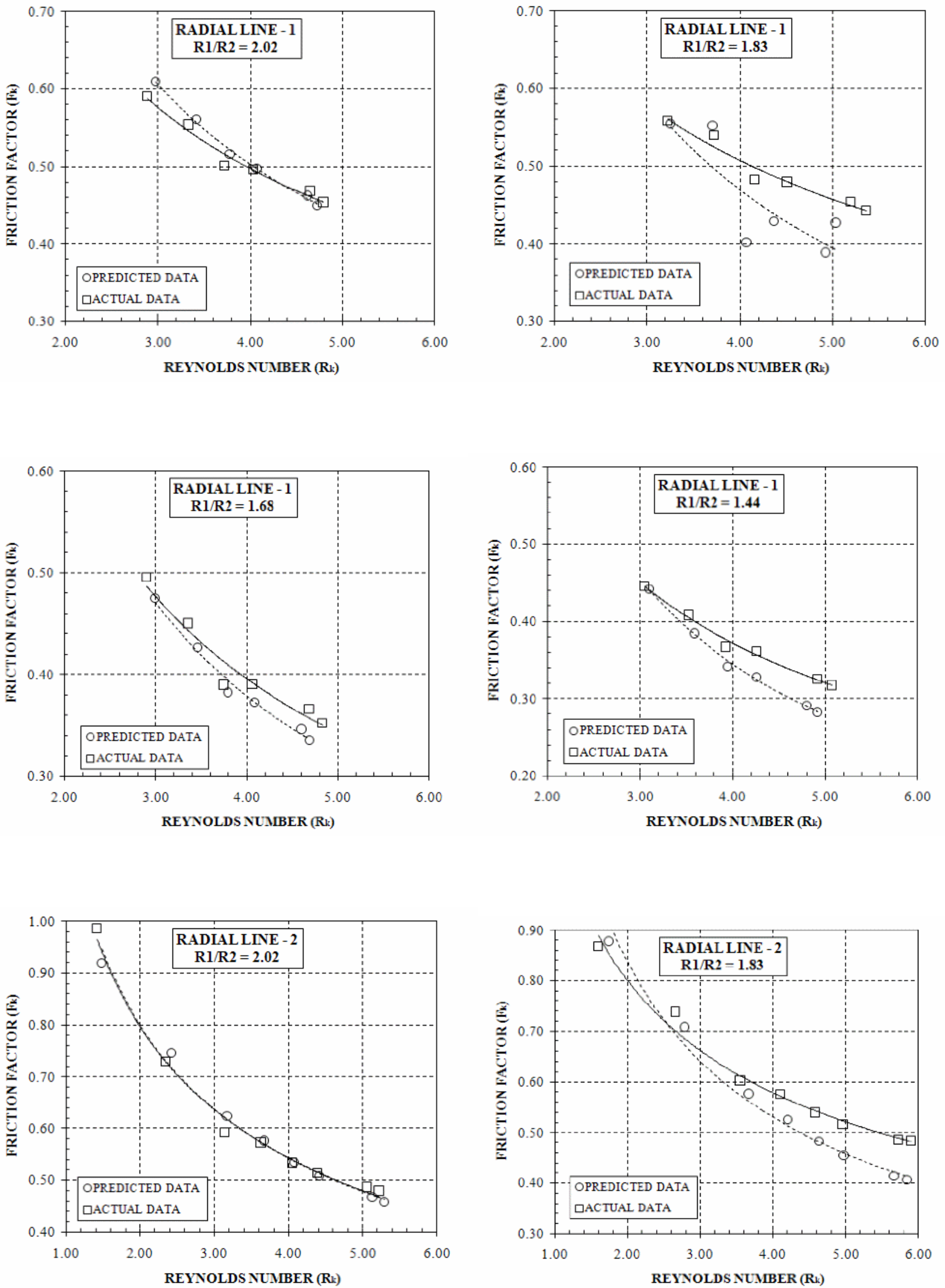

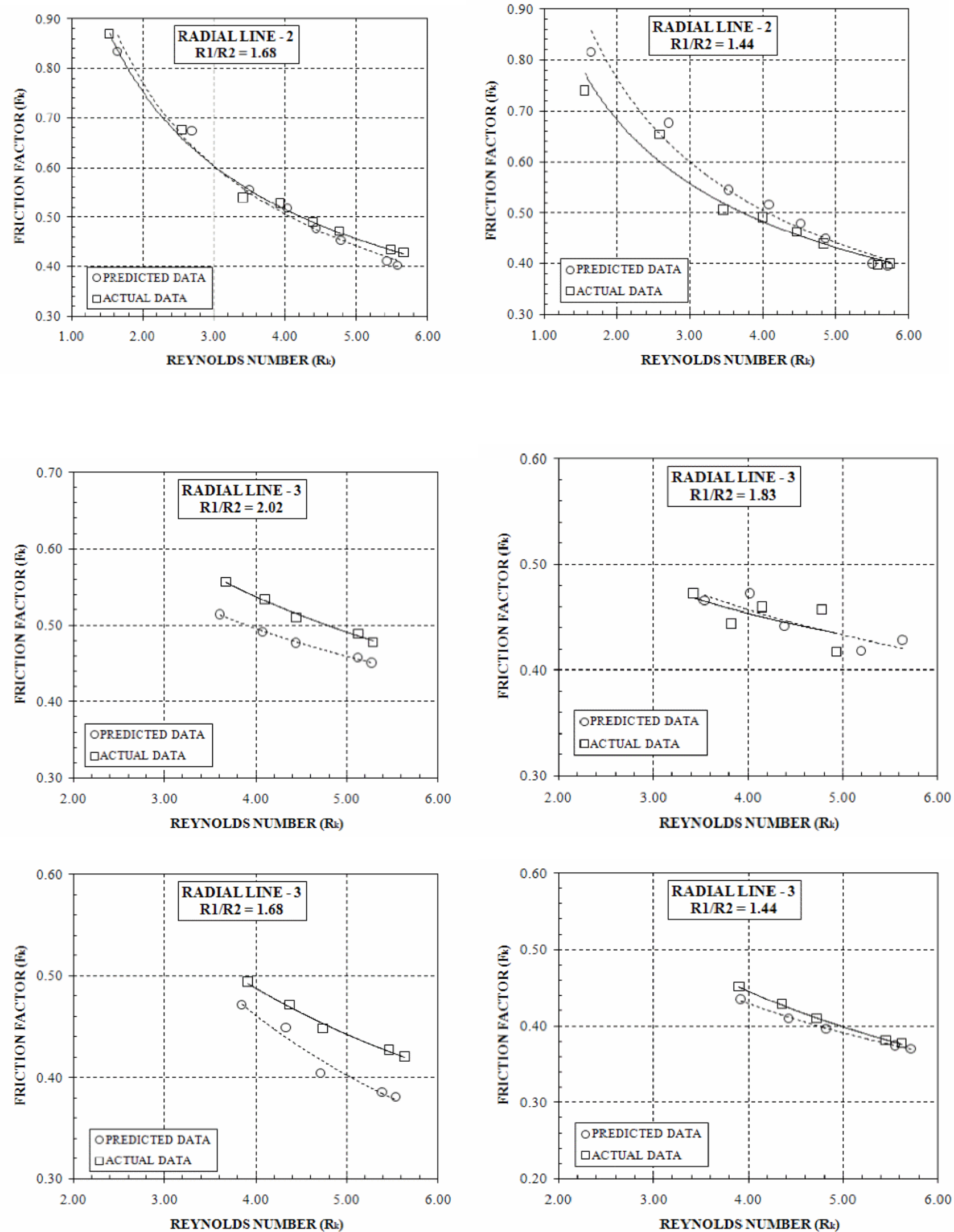

Fig.7. Variation of Friction Factor $\left(F_{k}\right)$ and Reynolds Number $\left(R_{k}\right)$ for Predicted and Actual Data for Different Radial Lines and Ratio of radii (R1/R2) 

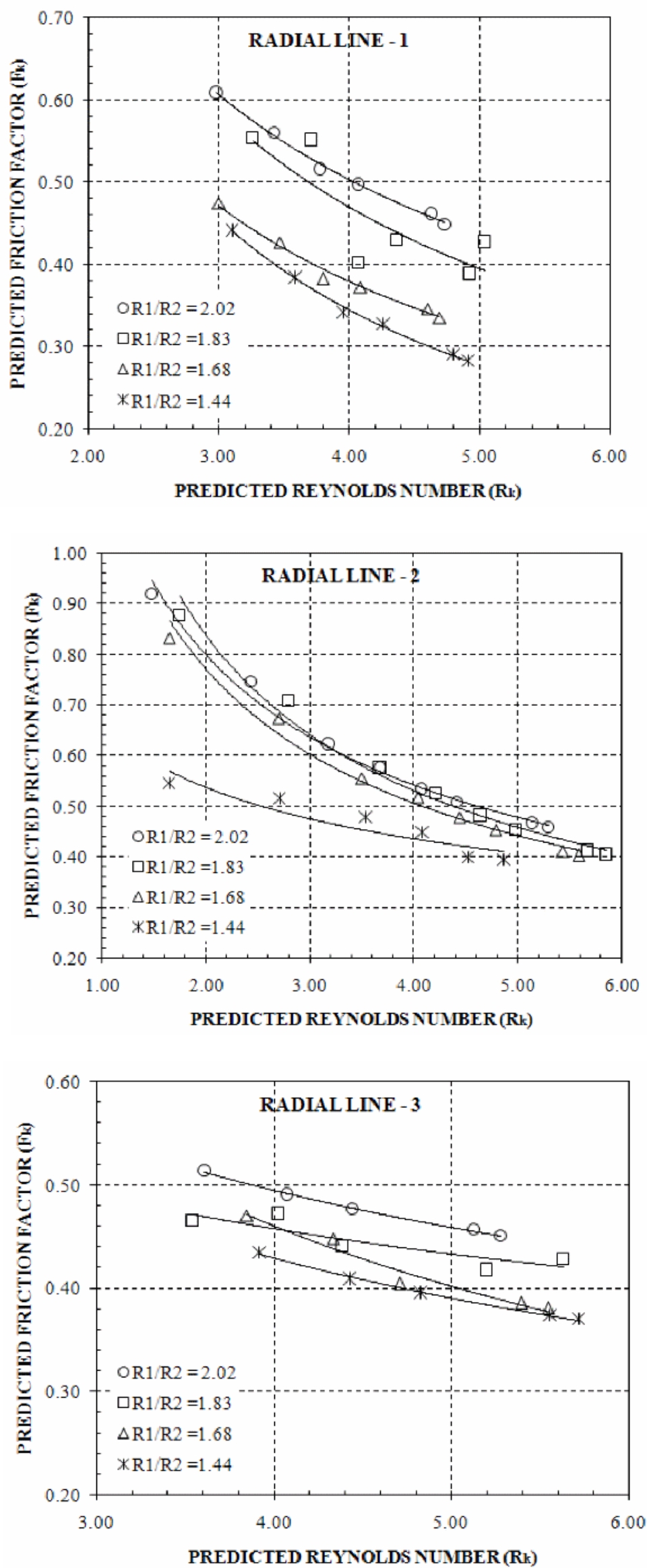

Fig.8. Variation of Predicted Friction Factor $\left(F_{k}\right)$ and Reynolds Number $\left(R_{k}\right)$ for Different Radial Lines and Ratio of radii (R1/R2) 

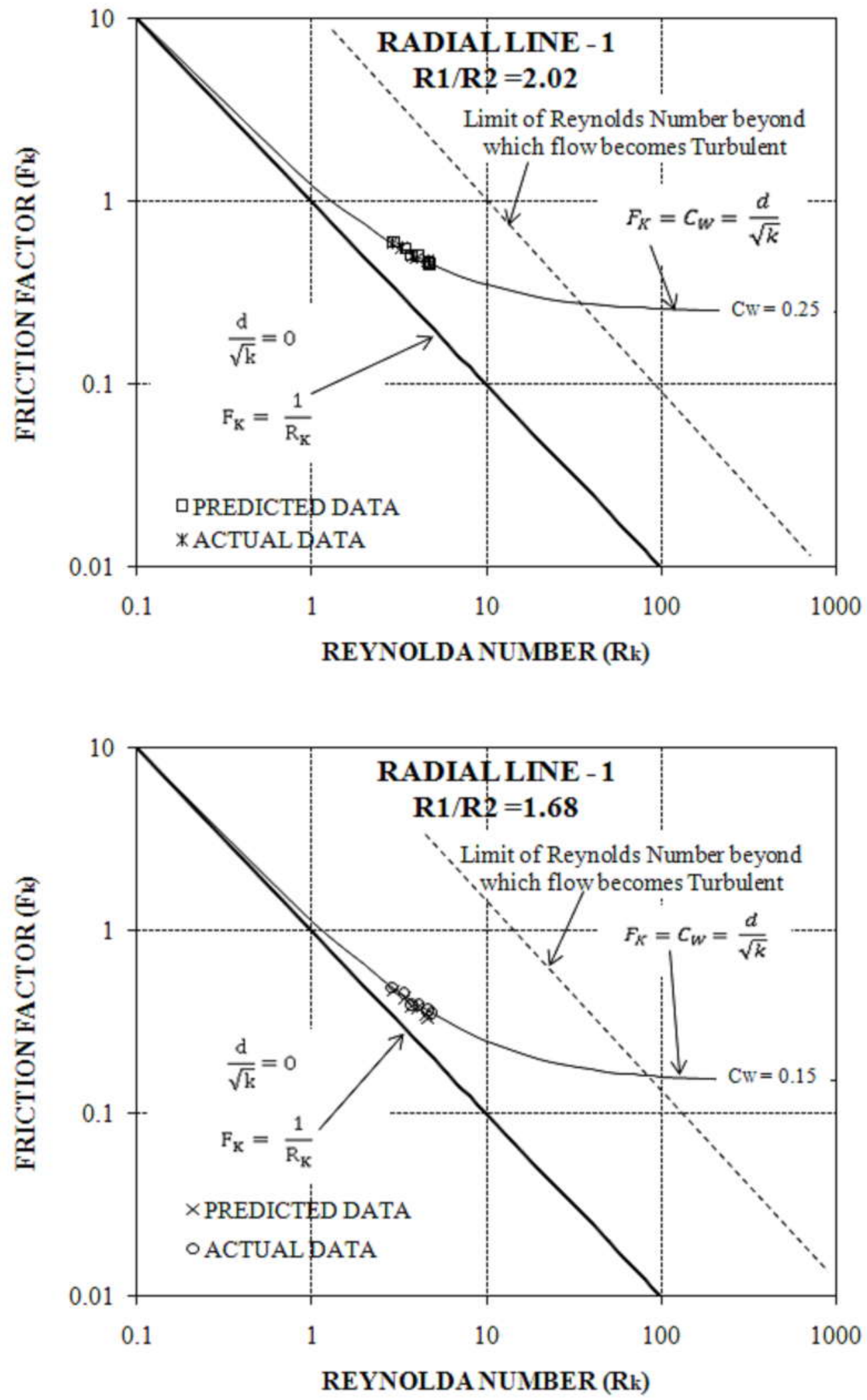

Fig.9.a. Variation of Friction Factor $\left(F_{k}\right)$ with Reynolds Number $\left(R_{k}\right)$ for Theoretical Values and for Predicted and Actual Data for Radial Line 1 with different Ratio of Radii (R1/R2) 

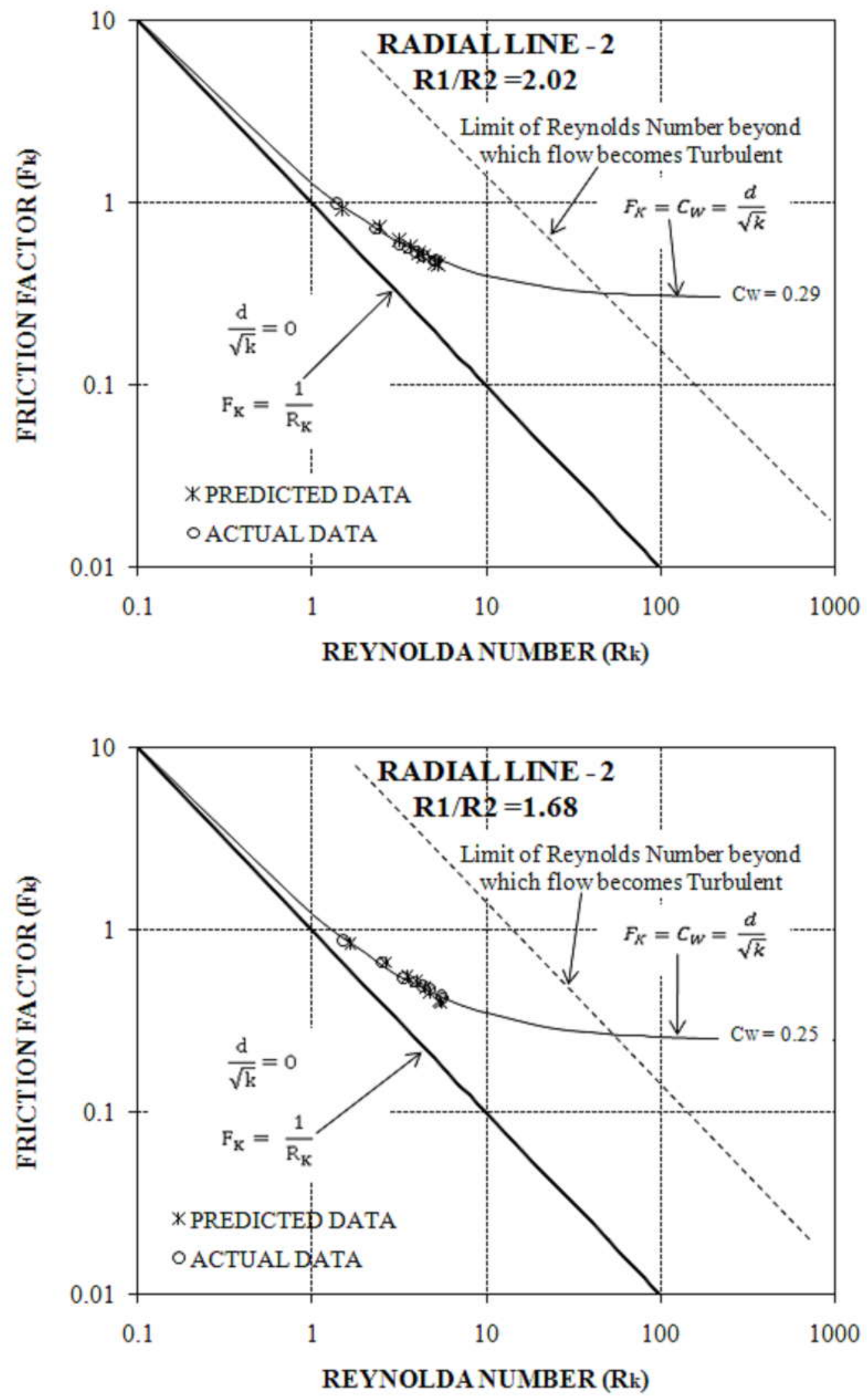

Fig.9.b. Variation of Friction Factor $\left(\mathrm{F}_{\mathrm{k}}\right)$ with Reynolds Number $\left(\mathrm{R}_{\mathrm{k}}\right)$ for Theoretical Values and for Predicted and Actual Data for Radial Line 2 with different Ratio of Radii (R1/R2) 

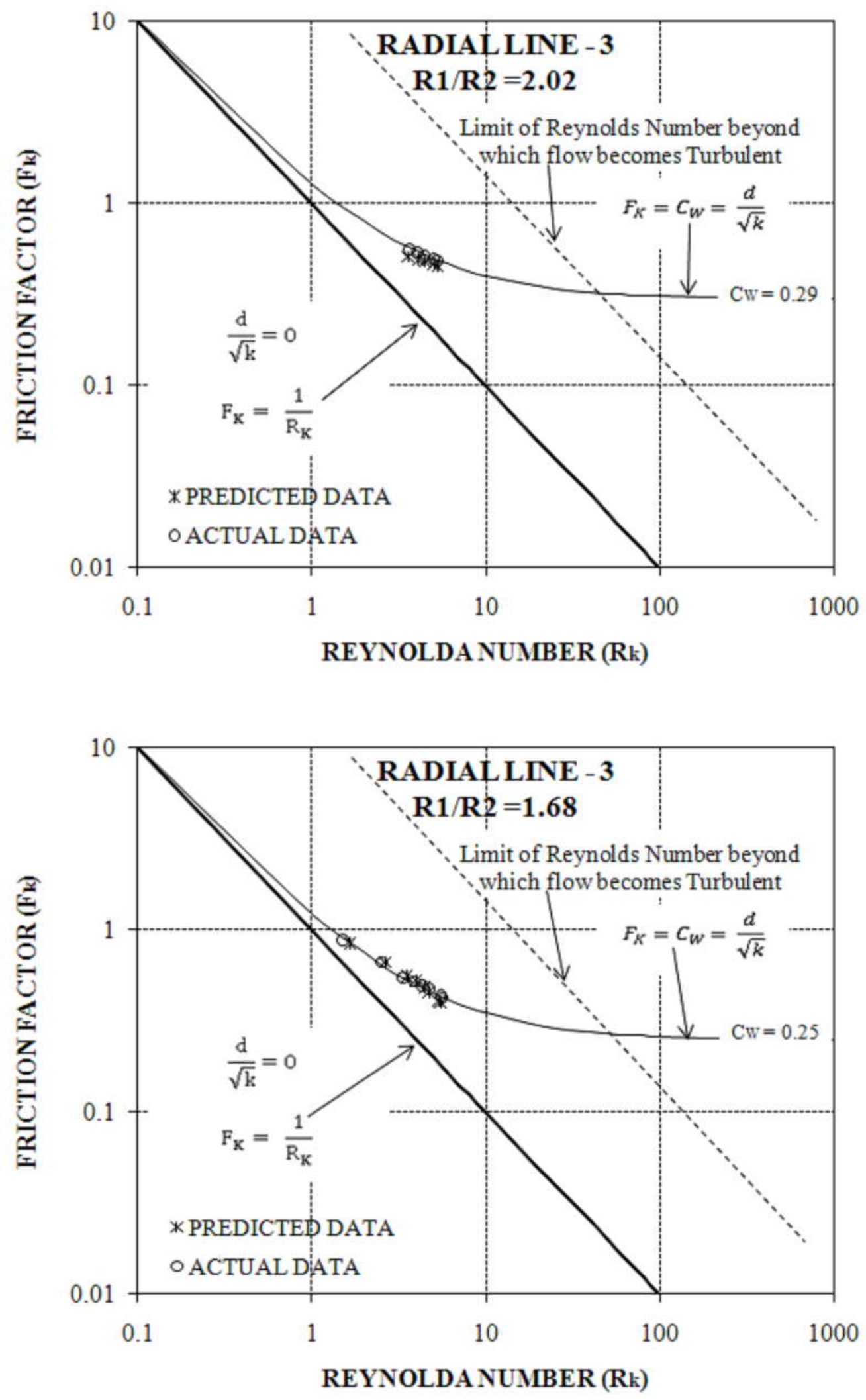

Fig.9.c. Variation of Friction Factor $\left(f_{k}\right)$ with Reynolds Number $\left(R_{k}\right)$ for Theoretical Values and for Predicted and Actual Data for Radial Line 3 with different Ratio of Radii (R1/R2) 